\title{
Verbal and Nonverbal Mismatch Negativity in Children with Typical Development: Variables Analysis
}

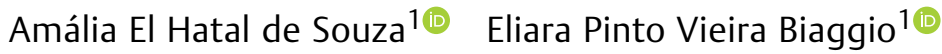 \\ ${ }^{1}$ Department of Speech Therapy, Universidade Federal de Santa \\ Maria, Santa Maria, RS, Brazil \\ Int Arch Otorhinolaryngol 2021;25(3):e399-e406. \\ Address for correspondence Amália El Hatal de Souza, Master, \\ Department of Speech Therapy, Universidade Federal de Santa Maria, \\ Avenida Roraima, 1000, prédio 26, Camobi, Santa Maria, \\ RS, 97105-900, Brazil (e-mail: amalia_souzaa@hotmail.com).
}

\begin{abstract}
Keywords

- evoked potentials

- auditory

- electrophysiology

- child

- hearing

Introduction Mismatch negativity (MMN) is a promising instrument for the investigation of different auditory disorders, as it does not need behavioral responses.

Objective To analyze the influence of the ear, gender and age variables in the MMN in children with typical development; and to compare the different measures of this potential, using verbal and nonverbal stimuli in the sample studied, providing reference values.

Methods Observational, descriptive, cross-sectional, quantitative study, with 23 children, aged from 5 to 11 years and 11 months old, divided by age group. Mismatch negativity was performed using verbal and nonverbal stimuli, and the data was analyzed by means of the statistical Student $t$-test.

Results No significant differences were noted for the ear, gender and age variables in the MMN with both stimuli. There were significant differences for the latency, duration and area variables when the stimuli were compared. The reference values established for nonverbal stimuli were: latency 249.8 milliseconds, amplitude $2.28 \mu \mathrm{v}$, duration 82.97 milliseconds, and area 137.3 microvolt $x$ microseconds $(\mu \vee x \mu s)$; as for the verbal stimuli, they were: latency 265.3 milliseconds, amplitude $-2.82 \mu \mathrm{v}$, duration 110.5 milliseconds, and area 225.5 microvolt $x$ microseconds ( $\mu \mathrm{Vx} \mu \mathrm{s})$.

Conclusion The variables studied did not influence the recordings of the MMN. Latency, duration and area of the MMN with verbal stimuli were higher. It was possible to furnish reference values for children with typical development in the age group studied.
\end{abstract}

\section{Introduction}

To achieve a complete and detailed auditory assessment, the peripheral auditory nervous system and the central nervous system (CNS) must be analyzed. For the evaluation of the CNS, electrophysiological measures have been widely used, as they make it possible for the hearing to be objectively and precisely evaluated. ${ }^{1}$ Among these measures, the negative component of the event-related potentials (ERP), mismatch negativity (MMN), stands out.

The MMN shows the ability of auditory processing, discriminating and memorizing in response to an electrical brain activity, ${ }^{2}$ which is triggered by the process of detecting auditory change presented in a sequence of acoustic stimuli stored in short-term auditory memory. ${ }^{3}$ This memory arises independently in the electrophysiological tracing, received

September 11, 2019

accepted

May 11, 2020

published online

September 24, 2020
DOI https://doi.org/

10.1055/s-0040-1713590.

ISSN 1809-9777.

\footnotetext{
(c) 2020. Fundação Otorrinolaringologia. All rights reserved.

This is an open access article published by Thieme under the terms of the Creative Commons Attribution-NonDerivative-NonCommercial-License, permitting copying and reproduction so long as the original work is given appropriate credit. Contents may not be used for commercial purposes, or adapted, remixed, transformed or built upon. (https://creativecommons.org/ licenses/by-nc-nd/4.0/)

Thieme Revinter Publicações Ltda., Rua do Matoso 170, Rio de Janeiro, RJ, CEP 20270-135, Brazil
} 
since it does not need the behavioral responses of the subjects. $^{2,4}$

This potential has its main origin in the auditory cortex, aided by the frontal cortex, the thalamus and the hippocampus. $^{5}$ Such potential can be elicited through nonverbal stimuli (tone burst), which differ in frequency, intensity or duration, and through verbal stimuli, in which syllable sets (consonant/vowel) are used. ${ }^{6}$

In child populations, MMN with latency values between 200 and 350 milliseconds can be observed, 7,8 always visualized after the after negative component response (N1), and it is obtained by the subtraction of responses to the frequent stimulus in relation to the rare stimulus. ${ }^{2}$

The main characteristic and advantage of the MMN is its being registered automatically, independently of attentional or behavioral aspects, which makes it possible to be registered in different populations. ${ }^{9-13}$ In addition, it may contribute in investigating cognitive processes and in complementing audiological assessment, since it is a promising tool for the analysis of the functioning of the cortical processing; it can thus aid in auditory diagnosis, monitoring, and rehabilitation prognosis. ${ }^{5}$

For it to happen, it is necessary to investigate how cortical structures function in normally hearing subjects, besides considering the maturation process, so that the MMN may be reliably obtained as a clinical tool. ${ }^{14}$ Hence, it is important to obtain reference values for the MMN for different age groups, methodologies and devices.

It should be highlighted as well that studies that describe reference values for MMN regarding verbal and nonverbal stimuli in typical children with the use of the Smart Ep device (Intelligent Hearing Systems, Miami, FL, USA) are not found in the literature.

Moreover, in spite of many possible applications of the MMN in the child population, ${ }^{8-13,15-20}$ there is still the need of studying MMN with verbal stimuli, as it is considered that this type of stimulus may complement central auditory processing evaluations, and bring light to the neurophysiological processes ${ }^{21}$ related to it.

Therefore, the objective of the present study was to analyze the influence of the ear, gender and age variables on the MMN in children with typical development, as well as comparing the different measures of this potential using verbal and nonverbal stimuli in the sample studied, thus providing reference values.

\section{Methodology}

The present study is characterized as observational, descriptive, cross-sectional and quantitative. It has been approved by the Research Ethics Committee of the institution where it was developed, under the number CAAE 81117517.0.0000.5346, and evaluation report 2.538.043.

Concerning ethical aspects, the parents and/or those responsible for the children were given an Informed Consent Form (ICF), and so did the children themselves receive the Informed Assent Form. Both documents contained the objectives of the study, the steps in carrying it out, and its risks and benefits. Furthermore, confidentiality of the data was guaranteed by the researchers signing the Confidentiality Agreement. It is highlighted that all norms and guidelines of the Resolution 466/12, which deals with researches with humans, were fully respected. The study was performed in an auditory electrophysiology outpatient center of a teaching clinic, between January 2018 and January 2019.

The sample was formed starting with the contact with four public and private schools, only two of which agreed to participate in the study. Then, 450 invitation notes were given out to the children in the age group ranging from 5 to 11 years and 11 months old, to carry out the assessments. The adults responsible for those children who showed interest in the assessments returned the invitation note with a telephone for contact, with which the researchers proceeded to schedule appointments.

The eligibility criteria established for the present research were: 1 ) children whose age ranged from 5 to 11 years and 11 months old, of both genders; 2) auditory thresholds within standards of normality in both ears ${ }^{22} ; 3$ ) bilateral type A tympanometric curve $\mathrm{e}^{23}$; 4) contralateral acoustic reflexes present in both ears ${ }^{23}$; 5 ) school performance adequate for their age, considering average grade $\geq$ to seven points, besides not having flunked any previous year; their parents and/or teachers report was also taken into account; and 6) typical phonological acquisition. The exclusion criteria were: 1 ) temporary auditory problems, as cases of otitis media, or permanent ones, as sensorineural hearing loss; 2) children with evident neurological, cognitive or psychiatric disorders; 3 ) scores $<46$ points on the Scale of Auditory Behavior $(\mathrm{SAB})^{24}$; 4) alterations on central auditory processing (CAP) tests; and 5) not cooperating to the conclusion of the evaluations selected for the present study.

Initially, 450 children were invited to take part in the present study. Out of these, only 87 showed interest in the evaluations; however, it was not possible to contact 6 of them, so 81 had an appointment scheduled. As the evaluations were being performed, 20 children did not attend, even after rescheduling. Thus, 61 children were assessed, 38 of which were excluded due to presenting alteration on the phonological system, on the acoustic immittance assessment, or on the CAP assessment, and/or due to not returning to conclude the evaluations. Hence, the sample for the present study was composed of 23 children, 10 males and 13 females (average age: 8.43 years old). Furthermore, they were subdivided into 2 groups according to their age, being arranged as follows: GROUP 1 composed of children between 5 and 7 years and 11 months old $(n=12)$; GROUP 2 composed of children whose age was between 8 and 11 years and 11 months old $(n=11)$.

We chose to evaluate children up to 12 years old, as it is believed that the electrophysiological responses of children at this age are similar to those found in adults. In addition, this division was elaborated thinking about the similar maturation process among the children of the same group and seeking a balance between the sample groups. The procedures for composing the sample were: anamnesis; noninstrumental language assessment, performed through oral report in the form of logical sequence, in which the different levels of 
language could be analyzed, such as phonological, semantic, pragmatic, morphological and syntactic aspects; visual inspection of the external acoustic meatus; pure-tone threshold audiometry (PTA); speech audiometry; acoustic immittance measurements; CAP assessment, performed by means of tests (dichotic digits test [DDT]) $^{25}$; random gap detection test $(\text { RGDT })^{26}$; speech perception in noise test (SPIN) ${ }^{25}$; maskinglevel difference $(M L D)^{27}$; and scale of auditory behavior (SAB). ${ }^{24}$ The CAP assessment was performed with the purpose of excluding alterations and complaints related to central auditory processing disorder (CAPD). Each test was performed in accordance with the criteria for normality found in the literature, according to the age group. ${ }^{25-28}$ Moreover, to reassure the integrity of the brainstem, the recording and the analysis of the brainstem auditory evoked potentials (BAEP) neurological protocol was performed following the norms of the equipment.

Such procedures were performed with the use of the following equipment: clinical otoscope (Welch-Allyn, Skaneateles Falls, NY) for the visual inspection of the external acoustic meatus; PTA, speech audiometry, and CAP behavioral tests performed with the use of the Fonix Hearing Evaluator, model FA 12 type I (Frye Electronics, Inc, Beaverton, OR, USA), and TDH-39P earphones (Telephonics, Farmingdale, NY, USA) in a sound booth; the acoustic immittance measurements were taken with the AT235 equipment (Interacoustics, Middelfart, Denmark), with $226 \mathrm{~Hz}$ probe tone; and the BAEP, neurologic protocol, was performed with the Smart Ep equipment, (Intelligent Hearing Systems, Miami, FL, USA).

After carrying out the procedures for selecting the sample, the next step was to record and analyze the negative behavior of the event-related potentials, the mismatch negativity (MMN). This potential was obtained by means of the Smart Ep twochannel equipment, attached to a conventional computer.

To obtain adequate recordings of the MMN, the skin of the child was previously sanitized, using Nuprep abrasive paste (Weaver and Company, Aurora, CO, USA) and common gauze. Afterwards, the silver electrodes were fastened with microporous tape on the four established regions. Thus, the active electrode was positioned at Fz, the ground electrode at Fpz, the central region of the forehead, and the reference electrodes at the right and left mastoids, in accordance with the International Electrode System 10-20. The Fz region was chosen for positioning the active electrode because it is considered to be one of the best positions to obtain the MMN. $^{2}$ The impedance values were maintained between 1 and 3 kohms to ensure recording reliability.

For this procedure, the children were seated on a comfortable chair, in a silent room, and were instructed to watch a children's film without sound on a computer; furthermore, they were oriented to pay attention only to the movie, ignoring the auditory stimuli, remaining quiet throughout the test. The film was chosen as a visual distractor as it is considered the most accepted means by the child population. ${ }^{2}$

This potential was elicited by pairs of nonverbal stimuli and pairs of verbal stimuli. First, the MMN research was performed using the pairs of nonverbal stimuli, in which the
$750 \mathrm{~Hz}$ tone burst stimulus was the frequent stimulus, and $1,000 \mathrm{~Hz}$ was the rare stimulus. In the sequence, MMN was elicited with verbal stimuli, with the syllable [da] as the frequent stimulus, and the syllable [ta] as the rare stimulus. The choice for the nonverbal pair of stimuli of $750 \mathrm{~Hz}$ and $1,000 \mathrm{~Hz}$ was due to considerations based on studies found in the national literature, ${ }^{15,18}$ besides their being the stimuli of less contrast in the Intelligent Hearing Systems equipment. The verbal stimuli [da] and [ta] were considered for presenting difference only in a sonority feature, making it easier for the child to ignore the stimulus presented. ${ }^{2}$

In relation to the established parameters to obtain the MMN, ${ }^{15,18}$ the stimuli were presented binaurally, via insert earphones, in the intensity of $60 \mathrm{dBnHL},{ }^{2}$ in alternating polarity, lasting 50,000 microseconds ( $\mu \mathrm{sec}$ ) for $750 \mathrm{~Hz}$, $10,000 \mu \mathrm{sec}$ for $1,000 \mathrm{~Hz}, 206,275 \mu \mathrm{sec}$ for the syllable [da], and $220,350 \mu \mathrm{sec}$ for the syllable [ta]. The ISI (interstimulus interval) was of 521 milliseconds for $750 \mathrm{~Hz}, 516$ milliseconds for $1,000 \mathrm{~Hz}, 320$ milliseconds for [da], and 306 milliseconds for [ta]. These values were expressed in these units in the manual of the equipment used.

The MMN was elicited by presenting the auditory stimuli through the oddball paradigm, presented at the speed of 1,9 stimuli per second. ${ }^{3}$ In total, 750 stimuli were presented, aiming at acquiring at least 150 rare stimuli, whose possibility of occurring is of $20 \%$ of the total stimuli. The presence of up to $10 \%$ of the number of artifacts of the final stimuli was considered. A low-pass filter of $1,0 \mathrm{~Hz}$ was used, as well as a high-pass filter of $30,0 \mathrm{~Hz}$, and the recording window was of 50 milliseconds prior to the stimulation (prestimulation) and 510 milliseconds posterior to it. ${ }^{29}$

In the electrophysiological tracing, the observed MMN measures were: latency (in milliseconds - ms), amplitude (in microvolt $-\mu \mathrm{V}$ ), duration (in milliseconds $-\mathrm{ms}$ ), and area (in microvolt $x$ microseconds $-\mu \mathrm{Vx} \mu \mathrm{s}$ ). The MMN was identified and marked as the peak of greatest negativity, followed by the peak of the $\mathrm{N} 1$ component, $^{2}$ in latency values between 200 and 350 milliseconds. ${ }^{7,8}$ As to the amplitude, it was considered from the peak of greatest negativity until the prestimulation line, ${ }^{29}$ excluding the participation of the $\mathrm{N} 1$ component. It was considered as MMN only the negative peak which presented minimum amplitude of $-0,3 \mu \mathrm{V} .{ }^{29}$ The duration of the MMN valley was also analyzed, considering the difference between initial latency (the time in milliseconds in which negativity began in the resulting wave) and the displacement latency (the time in milliseconds in which negativity reached baseline activity, or the point zero of the resulting wave). ${ }^{13}$ As for the area of the MMN, it was automatically measured by the equipment.

It should be highlighted that all the exams performed in the present study were analyzed and marked by two professionals with theoretical and practical experience in auditory electrophysiology. It is noteworthy that there was agreement on MMN markings in all exams analyzed.

It is also emphasized that the procedures of the present study were performed in two sessions. On the first one, the sample selecting procedures were performed. On the second, the MMN was performed. Furthermore, the MMN recording 

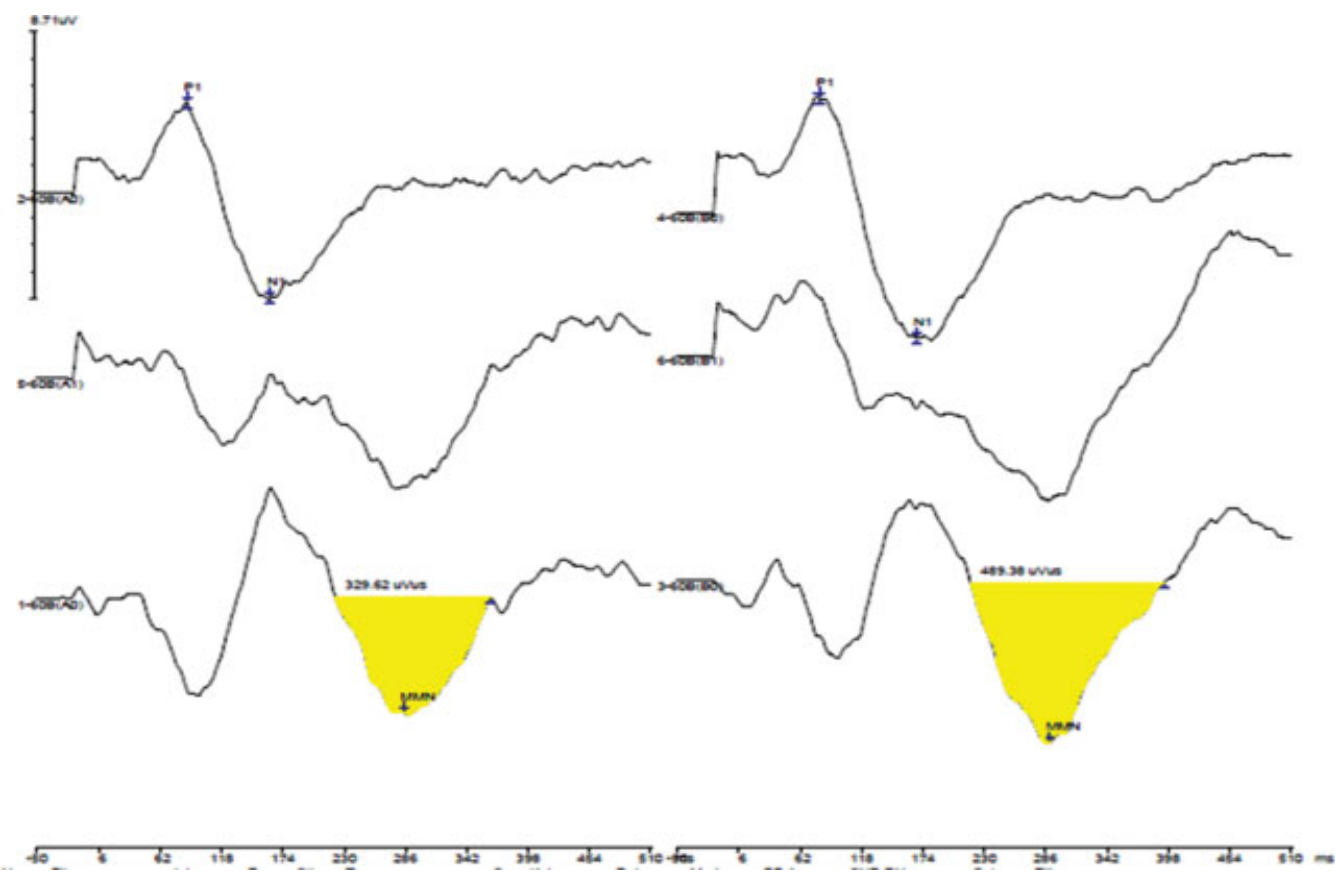

Fig. 1 MMN plot for the contrasts of [da] (frequent) and [ta] (rare) and the resulting (frequent) stimuli of a sample subject.

was repeated. Both sessions lasted $\sim 50$ minutes, with breaks for rest.

All the data obtained in the present study were tabulated on Microsoft Excel 2010. For the analysis and comparison of the data, the computing software Statistical Package for the Social Sciences (SPSS) was used.

The normality of the data was tested through the ShapiroWilk test, to identify whether the samples originated from normal populations. Thus, respecting the normality of the data, the Student $t$-test was used. The confidence intervals (CIs) were built with $95 \%$ statistical confidence $(p<0.05)$. Considering the sample size, in relation to the age variable, it was divided into two groups, as explained in the methodology section, so the choice of the Student $t$-test was the most appropriate.
To illustrate the potential studied, a record of one of the sample subjects is presented (-Fig. 1).

\section{Results}

No child needed to be excluded from the sample, as all of them presented responses on the MMN for both stimuli researched.

On - Table 1, the comparison between the average values for latency (ms), amplitude ( $\mu \mathrm{v})$, duration (ms) and area (msX $\mu \mathrm{v})$ of the MMN in children with typical development for the verbal and nonverbal stimuli between the right ear (RE) and left ear (LE) is presented. For this purpose, the Student $t$-test was used.

Table 1 Values for latency (ms), amplitude ( $\mu \mathrm{v})$, duration (ms) and area (msX $\mu \mathrm{v}$ ) of the mismatch negativity for verbal and nonverbal stimuli, considering the evaluated ear variable $(n=23)$

\begin{tabular}{|c|c|c|c|c|c|c|c|c|c|c|c|}
\hline & & \multicolumn{4}{|c|}{$750 \mathrm{~Hz} \mid 1,000 \mathrm{~Hz}(n=23)$} & \multirow[t]{2}{*}{ p-value } & \multicolumn{4}{|c|}{$[\mathrm{DA}] /[\mathrm{TA}](n=23)$} & \multirow[t]{2}{*}{ p-value } \\
\hline & & Average & Min & Max & SD & & Average & Min & Max & SD & \\
\hline \multirow[t]{2}{*}{ Latency (ms) } & RE & 249.09 & 174 & 287 & 27.9 & \multirow[t]{2}{*}{0.088} & 265.73 & 178 & 294 & 29.8 & \multirow[t]{2}{*}{0.091} \\
\hline & LE & 250.48 & 162 & 286 & 33.1 & & 264.82 & 167 & 295 & 27.8 & \\
\hline \multirow[t]{2}{*}{ Amplitude ( $\mu \mathrm{v})$} & RE & -2.33 & -0.76 & -4.44 & 1.01 & \multirow[t]{2}{*}{0.057} & -3.25 & -0.99 & -6.16 & 1.33 & \multirow[t]{2}{*}{0.36} \\
\hline & $\mathrm{LE}$ & -2.12 & -0.75 & -4.63 & 1.41 & & -2.76 & -0.68 & -5.84 & 2.18 & \\
\hline \multirow[t]{2}{*}{ Duration (ms) } & RE & 84.21 & 35 & 149 & 34.5 & \multirow[t]{2}{*}{0.788} & 110.43 & 60 & 168 & 35.5 & \multirow[t]{2}{*}{0.784} \\
\hline & LE & 81.73 & 32 & 123 & 27.2 & & 113.42 & 56 & 183 & 38.4 & \\
\hline \multirow[t]{2}{*}{ Area $(\mu \mathrm{V} x \mu \mathrm{s})$} & RE & 118.2 & 43.5 & 288.7 & 77.1 & \multirow[t]{2}{*}{0.099} & 222.49 & 30.2 & 431.62 & 127 & \multirow[t]{2}{*}{0.088} \\
\hline & LE & 118.53 & 42.96 & 275.4 & 87 & & 228.45 & 50.44 & 511.42 & 139 & \\
\hline
\end{tabular}

Abbreviations: Hz, hertz; LE, left ear; ms, measure in milliseconds; $n$, number of subjects in the sample; RE, right ear; SD, standard deviation $\mu \mathrm{v}$, measure in microvolts: $\mu \mathrm{Vx} \mu \mathrm{s}$, microvolt $\mathrm{x}$ microseconds.

*Student statistical $t$-test. 
Table 2 Values for latency (ms), amplitude $(\mu \mathrm{v})$, duration ( $\mathrm{ms})$, and area ( $\mu \mathrm{Vx} \mu \mathrm{s})$ between both genders for verbal and nonverbal stimuli of the mismatch negativity $(n=23)$

\begin{tabular}{|c|c|c|c|c|c|c|c|c|c|c|c|c|c|}
\hline \multirow[t]{2}{*}{ MMN } & & \multicolumn{4}{|c|}{$750 \mathrm{~Hz} / 1,000 \mathrm{~Hz}(n=23)$} & \multirow[t]{2}{*}{$\mathrm{N}$} & \multirow[t]{2}{*}{ p-value } & \multicolumn{4}{|c|}{$[\mathrm{DA}] /[\mathrm{TA}](n=23)$} & \multirow[t]{2}{*}{$\mathrm{N}$} & \multirow[t]{2}{*}{ p-value } \\
\hline & & Average & Min & Max & SD & & & Average & Min & Max & SD & & \\
\hline \multirow{2}{*}{$\begin{array}{l}\text { Latency } \\
\text { (ms) }\end{array}$} & Fem & 243.15 & 168 & 286.5 & 31.44 & 13 & \multirow[t]{2}{*}{0.734} & 267 & 172.5 & 284 & 23.62 & 13 & \multirow[t]{2}{*}{0.734} \\
\hline & Male & 258.4 & 209.5 & 284.5 & 23.04 & 10 & & 263.05 & 209.5 & 288.5 & 23.62 & 10 & \\
\hline \multirow{2}{*}{$\begin{array}{l}\text { Amplitude } \\
(\mu v)\end{array}$} & Fem & -2.26 & -1.21 & -4.08 & 0.978 & 13 & \multirow[t]{2}{*}{0.589} & -3.01 & -0.83 & -5.73 & 2.616 & 13 & \multirow[t]{2}{*}{0.589} \\
\hline & Male & -2.31 & -0.75 & -4.02 & 1.254 & 10 & & -2.57 & -0.93 & -4.74 & 1.061 & 10 & \\
\hline \multirow{2}{*}{$\begin{array}{l}\text { Duration } \\
\text { (ms) }\end{array}$} & Fem & 73.57 & 33.5 & 122.5 & 25.18 & 13 & \multirow[t]{2}{*}{0.171} & 119.88 & 70 & 165.5 & 34.16 & 13 & \multirow[t]{2}{*}{0.171} \\
\hline & Male & 95.2 & 43.5 & 147 & 31.75 & 10 & & 98.3 & 59.5 & 162.5 & 37.42 & 10 & \\
\hline \multirow{2}{*}{$\begin{array}{l}\text { Area } \\
(\mu \vee x \mu s)\end{array}$} & Fem & 142.4 & 39.52 & 512.2 & 135.5 & 13 & \multirow[t]{2}{*}{0.171} & 264.45 & 40.32 & 443.05 & 132 & 13 & \multirow[t]{2}{*}{0.094} \\
\hline & Male & 130.71 & 53.59 & 264.7 & 84.62 & 10 & & 174.78 & 30.22 & 420.52 & 112.6 & 10 & \\
\hline
\end{tabular}

Abbreviations: fem, female; $\mathrm{Hz}$, hertz; male, male; MMN, mismatch negativity; ms, measure in milliseconds; $\mathrm{n}$, number of subjects in the sample; SD, standard deviation $\mu \mathrm{v}$, measure in microvolts: $\mu \mathrm{V} \times \mu \mathrm{s}$, microvolt $\mathrm{x}$ microseconds;.

*Student statistical t-test.

- Table 1 presents the values for latency (ms), amplitude $(\mu \mathrm{v})$, duration (ms) and area (msX $\mu \mathrm{v})$ of the mismatch negativity for verbal and nonverbal stimuli, considering the evaluated ear variable $(n=23)$.

Considering that there was no statistically significant difference between the ears, the choice was for analyzing the influence of gender on the MMN component. Hence, the average values between the ears were analyzed by means of the Student $t$-test ( - Table 2 ).

- Table 2 presents the values for latency ( $\mathrm{ms}$ ), amplitude $(\mu \mathrm{v})$, duration $(\mathrm{ms})$, and area $(\mu \mathrm{Vx} \mu \mathrm{s})$ between both genders for verbal and nonverbal stimuli of the mismatch negativity $(n=23)$.

It was further sought to analyze the influence of age in relation to the values for latency (ms), amplitude ( $\mu v)$, duration (ms) and area (msX $\mu \mathrm{v}$ ) of the MMN for verbal and nonverbal stimuli ( - Table 3). For this statistical analysis, the statistical Student $t$-test was used.
- Table 3 presents the values for latency (ms), amplitude $(\mu \mathrm{v})$, duration (ms) and area $(\mu \mathrm{Vx} \mu \mathrm{s})$ between the different age groups for verbal and nonverbal stimuli of the mismatch negativity $(n=23)$.

On the following table, the comparison of the measures of latency (ms), amplitude ( $\mu \mathrm{v})$, duration ( $\mathrm{ms}$ ) and area ( $\mu \mathrm{Vx} \mu \mathrm{s})$ of the MMN between the verbal and nonverbal stimuli in children with typical development is presented. The test used for this analysis was the Student $t$-test.

- Table 4 presents the comparison of the averages of the latency (ms), amplitude ( $\mu \mathrm{v})$, duration ( $\mathrm{ms}$ ) and area ( $\mu \mathrm{Vx \mu s}$ ) variables of the MMN between verbal and nonverbal stimuli in children with typical development $(n=23)$.

Following the presented analysis, it was possible to establish reference values for the MMN with verbal and nonverbal stimuli in children with typical development in the age group ranging from 5 to 11 years and 11 months old (- Table 5 ).

Table 3 Values for latency (ms), amplitude $(\mu \mathrm{v})$, duration (ms) and area ( $\mu \mathrm{Vx} \mu \mathrm{s}$ ) between the different age groups for verbal and nonverbal stimuli of the mismatch negativity $(n=23)$

\begin{tabular}{|c|c|c|c|c|c|c|c|c|c|c|c|c|c|}
\hline \multirow[t]{2}{*}{ MMN } & & \multicolumn{4}{|c|}{$750 \mathrm{~Hz} / 1,000 \mathrm{~Hz}(n=23)$} & \multirow[t]{2}{*}{$\mathrm{N}$} & \multirow[t]{2}{*}{ p-value } & \multicolumn{4}{|c|}{$[\mathrm{DA}] /[\mathrm{TA}](n=23)$} & \multirow[t]{2}{*}{$\mathrm{N}$} & \multirow[t]{2}{*}{ p-value } \\
\hline & & Average & Min & Max & SD & & & Average & Min & Max & SD & & \\
\hline \multirow{2}{*}{$\begin{array}{l}\text { Latency } \\
\text { (ms) }\end{array}$} & G1 & 255.66 & 213 & 290.5 & 28.47 & 12 & \multirow[t]{2}{*}{0.313} & 273.16 & 266.5 & 294.5 & 23.55 & 12 & \multirow[t]{2}{*}{0.16} \\
\hline & G2 & 243.36 & 168 & 272.3 & 28.58 & 11 & & 256.68 & 172.5 & 288.5 & 30.56 & 11 & \\
\hline \multirow{2}{*}{$\begin{array}{l}\text { Amplitude } \\
(\mu \mathrm{v})\end{array}$} & G1 & -2.37 & -0.75 & -4.73 & 1.26 & 12 & \multirow[t]{2}{*}{0.703} & -2.66 & -0.83 & -4.88 & 1.22 & 12 & \multirow[t]{2}{*}{0.697} \\
\hline & G2 & -2.19 & -1.32 & -4.02 & 0.89 & 11 & & -3.01 & -1.88 & -5.55 & 2.76 & 11 & \\
\hline \multirow{2}{*}{$\begin{array}{l}\text { Duration } \\
\text { (ms) }\end{array}$} & G1 & 75.7 & 33.5 & 122.5 & 29.58 & 12 & \multirow[t]{2}{*}{0.227} & 99.29 & 61 & 149.5 & 29.59 & 12 & \multirow[t]{2}{*}{0.126} \\
\hline & $G 2$ & 90.9 & 55 & 147 & 28.94 & 11 & & 122.72 & 65 & 165.5 & 40.57 & 11 & \\
\hline \multirow{2}{*}{$\begin{array}{l}\text { Area } \\
(\mu \vee x \mu s)\end{array}$} & G1 & 160.45 & 39.52 & 512.17 & 142.1 & 12 & \multirow[t]{2}{*}{0.321} & 177.77 & 73.85 & 441.45 & 117.1 & 12 & \multirow[t]{2}{*}{0.063} \\
\hline & G2 & 112.09 & 49.94 & 264.65 & 70.68 & 11 & & 277.49 & 100.7 & 443.05 & 126.8 & 11 & \\
\hline
\end{tabular}

Abbreviations: Group 1, children with age between 5 years and 7 years and 11 months old; Group 2, children with age between 8 and 11 years and 11 months old; Hz, hertz; MMN, mismatach negativity; ms, measure in milliseconds; n, number of subjects in the sample; SD, standard deviation $\mu$, measure in microvolts; $\mu \mathrm{V} x \mu \mathrm{s}$, microvolt $\mathrm{x}$ microseconds.

*Student statistical t-test. 
Table 4 Comparison of the averages of the latency (ms), amplitude ( $\mu \mathrm{v})$, duration (ms) and area ( $\mu \mathrm{Vx} \mu \mathrm{s})$ variables of the MMN between verbal and nonverbal stimuli in children with typical development $(n=23)$

\begin{tabular}{|c|c|c|c|c|c|c|c|c|c|}
\hline \multirow[t]{2}{*}{ MMN } & \multicolumn{4}{|c|}{$750 / 1,000 \mathrm{~Hz}(n=23)$} & \multicolumn{4}{|c|}{$[\mathrm{DA}] /[\mathrm{TA}](n=23)$} & \multirow[t]{2}{*}{ p-value } \\
\hline & Average & Min & Max & SD & Average & Min & Max & SD & \\
\hline Latency (ms) & 249.8 & 168 & 290.5 & 28.57 & 265.3 & 172.5 & 294.5 & 27.8 & $0.006^{*}$ \\
\hline Amplitude $(\mu v)$ & -2.28 & -0.75 & -4.73 & 1.07 & -2.82 & -0.93 & -5.75 & 2.06 & 0.279 \\
\hline Duration (ms) & 82.97 & 33.5 & 131.5 & 29.63 & 110.5 & 61 & 165.5 & 36.49 & $0.007^{*}$ \\
\hline $\begin{array}{l}\text { Area } \\
(\mu \vee x \mu s)\end{array}$ & 137.3 & 39.52 & 512.7 & 113.9 & 225.5 & 30.22 & 443.05 & 129.5 & $0.019^{*}$ \\
\hline
\end{tabular}

Abbreviations: $\mathrm{Hz}$, hertz; LE, left ear; max, maximum; min, minimum; MMN, mismatch negativity; ms, measure in milliseconds; RE, right ear; SD, standard deviation $\mu \mathrm{v}$, measure in microvolts; $\mu \mathrm{Vx} \mu \mathrm{s}$, microvolt $\mathrm{x}$ microseconds.

*statistically significant value.

*Student's statistical $t$-test.

Table 5 Reference values for latency (ms), amplitude ( $\mu \mathrm{v})$, duration (ms) and area ( $\mu \mathrm{Vx} \mu \mathrm{s}$ ) variables of the MMN between verbal and nonverbal stimuli in children with typical development $(n=23)$

\begin{tabular}{|l|l|l|l|l|}
\hline \multirow{2}{*}{ MMN } & \multicolumn{2}{|l|}{$\begin{array}{l}750 \mathrm{~Hz} / 1000 \mathrm{~Hz} \\
(\boldsymbol{n}=\mathbf{2 3})\end{array}$} & \multicolumn{2}{l|}{$\begin{array}{l}\text { [DA] / [TA] } \\
(\boldsymbol{n}=\mathbf{2 3})\end{array}$} \\
\cline { 2 - 5 } & Average & SD & Average & SD \\
\hline Latency $(\mathrm{ms})$ & 249.8 & 28.57 & 265.3 & 27.8 \\
\hline Amplitude $(\mu \mathrm{v})$ & -2.28 & 1.07 & -2.82 & 2.06 \\
\hline Duration $(\mathrm{ms})$ & 82.97 & 29.63 & 110.5 & 36.49 \\
\hline Area $(\mu \mathrm{Vx} \mu \mathrm{s})$ & 137.3 & 113.9 & 225.5 & 129.5 \\
\hline
\end{tabular}

Abbreviations: $\mathrm{Hz}$, hertz; MMN, mismatch negativity; ms, measure in milliseconds; SD, standard deviation; $\mu \mathrm{v}$, measure in microvolts; $\mu \mathrm{Vx} \mu \mathrm{s}$, microvolt x microseconds.

- Table 5 presents reference values for latency (ms), amplitude $(\mu \mathrm{v})$, duration $(\mathrm{ms})$ and area $(\mu \mathrm{Vx} \mu \mathrm{s})$ variables of the MMN between verbal and nonverbal stimuli in children with typical development $(n=23)$.

\section{Discussion}

The results obtained in the present study make possible the visualization that the MMN elicited through nonverbal stimuli (750 and $1,000 \mathrm{~Hz}$ ) and by verbal stimuli ([da/ta]) was present and very identifiable in all children of the sample. This finding agrees with other studies performed with child populations in groups of children without alterations, ${ }^{8,9,13,20}$ which suggests that children with typical development (TD) distinguish different acoustic stimuli independently of attentional factors.

Considering the values for latency, duration, amplitude and area of the MMN for both stimuli studied, it was noted that there was no statistically significant difference between the right ear and the left ear (-Table 1). Researches performed with this potential also did not observe difference between the ears, verifying similitude in the maturing process between the right and the left side in the child population $^{8,13,17}$ and in the adult population. ${ }^{30}$ Based on these, it is possible to infer that the maturing process of the ear canal is similar between right and left ear, with simultaneous development of hearing skills of both.

In the present study, the influence of gender in relation to the studied variables was also analyzed, and no statistically significant differences between them were observed (-Table 2), which shows that thematuration of the ear canaloccurs synchronically between genders. Another research did not show statistically significant differences between the genders in a child population. ${ }^{8}$ The study points to amplitude of MMN tending to be higher among females in relation to males when verbal stimuli are used; however, this does not occur with latency, which presents higher values for males. $^{31}$ The authors believe that higher amplitudes among females may be related to a higher bundling of enveloped neurons, as well as to the better synchrony of the neural network. Nevertheless, such findings were not evidenced in the present study. Therefore, it is understood that the values obtained in the present study can be used for both genders, since no statistically significant differences between them were found, as mentioned above.

It is understood that the maturational process of the ear canal interferes with the latency and amplitude values. However, no statistically significant differences were observed in relation to the chronological age of the children, both for verbal and for nonverbal stimuli ( - Table 3 ). These results corroborate another study performed with children without auditory complaints, in which no association of age with electrophysiological measures was found. ${ }^{8}$ Such findings were not the expected, since, as in the other auditory evoked potentials, it was expected an effect of maturation on the different analyzed variables of the MMN , as it was observed in a previous study. ${ }^{16}$ It is emphasized that, even though no statistically significant differences were verified, a decrease of latency values as the age increased was observed, suggesting that the ear canal of these children is still in the process of maturation. It should be noted that, possibly, no statistically significant differences were evidenced in this analysis because both groups presented similar minimum and maximum values. Attention is called to the fact that the age group studied is composed of children in the process of maturation of the central auditory nervous system (CANS), and that beginning at $\sim 12$ years 
old the responses of this potential become similar to those of adults. $^{32}$

Besides the maturational process of the ear canal, other factors may influence the latency and amplitude values of the ERP, as the type of paradigm and stimuli used to obtain them. ${ }^{33}$ In the present study, the oddball paradigm was used to elicit the MMN, with verbal and nonverbal stimuli presented to obtain the recordings of this potential. For nonverbal stimuli, the pairs of $750 \mathrm{~Hz}$ (frequent stimulus) and $1,000 \mathrm{~Hz}$ (rare stimulus) were used. It is noted that the literature recommends that differences $>10 \%$ be avoided, in order not to impair the recording of the MMN, as there may occur an involuntary change of attention to the stimulus, being contaminated by another potential characterized as a positive wave peak denominated with the P3a. ${ }^{34}$ Although in the present study the difference between these stimuli is $>10 \%$, it was possible to elicit the MMN in all children of the sample, the same that happened in other studies with child populations which also obtained the MMN for these stimuli. ${ }^{15,18}$

In relation to the verbal stimuli, pairs of syllables were used, the syllable [da] being the frequent stimulus, and the syllable [ta] the rare stimulus. These stimuli present difference only in the temporal relation regarding the release of the plosive and the beginning of the process of vowel sounding (voice onset time [VOT]), determined in the temporal aspect, whose measure is presented in milliseconds. Moreover, these pairs of stimuli were chosen because they present few phonemic contrasts, making it easier for the child to ignore the presented stimuli. ${ }^{35}$

When the stimuli were compared ( - Table 4), statistically significant differences were observed for the latency, duration and area variables of the MMN, showing that the verbal stimulus presents higher values in relation to the nonverbal stimulus for all the assessed variables; however, for amplitude, such difference was not verified, because it is believed that these values present greater response variability in relation to the other variables analyzed. ${ }^{10}$ The verbal stimulus presents a greater linguistic load, so it is more complex to process the acoustic information. ${ }^{10}$ In addition, these stimuli present different physical characteristics, which justifies the findings resulted from the present study.

The results were similar to the findings of a study ${ }^{10}$ that noted statistically significant difference for the latency values in the group of children without auditory alterations. Nonetheless, in the amplitude values, this difference was not found, thus agreeing with the results obtained in the present study. In another study, ${ }^{11}$ statistically significant difference was also evidenced when comparing the stimuli for latency, presenting higher values for verbal stimuli. The amplitude for the nonverbal stimuli, on the other hand, was higher, disagreeing with the present study in relation to amplitude values.

Other electrophysiological measures may be analyzed on the recording of the MMN, such as the duration and area values, although they are less usual. On the consulted scientific literature, there was only one study that analyzed duration values. ${ }^{13}$ In the referred study, verbal stimuli were used with average values similar to those of the present study. It is understood that the duration of the MMN valley is the differ- ence between the initial latency, that is, the time (milliseconds) that the negativity of the component appears on the resulting wave, and the displacement latency, which represents the time in which the negativity reaches the baseline activity, or the point zero on the resulting wave. Considering the lack of studies analyzing the duration values, the discussion of this measure is thus limited.

The area values of the MMN are dependent on the amplitude markings, and this measure reflects the size of the electrical activity in microvolt $\mathrm{x}$ microseconds ( $\mu \mathrm{Vx} \mu \mathrm{s})$. Attention is called to the fact that area marking is performed only with the Smart Ep equipment and only two studies with child population ${ }^{13,36}$ that used this equipment were found, of which just one performed this analysis. ${ }^{13}$ The data obtained in the referred study diverge from the ones from the present study, as higher area values were found. Such datum may be justified by the type of population studied, by the stimuli used and by the chronological age of the children belonging to both studies.

In addition to the performed analyses, the present study made possible the description of latency, amplitude, duration and area values for the MMN for verbal and nonverbal stimuli in children with TD, aged from 5 years to 11 years and 11 months old. The average values for each variable of this component are shown on - Table 5 .

The values obtained for latency in the present study are close to those mentioned in the literature regarding child population without language and hearing alterations. The fact that the MMN record was binaural may have been responsible for the greater amplitudes than those mentioned in the literature. ${ }^{7,9,13,15,18,19}$ Furthermore, the present study points out reference values for the MMN with verbal and nonverbal stimuli, on the Smart EP equipment, in children with typical development, aged from 5 to 11 years and 11 months old. Moreover, it makes possible knowing the values for duration and area values, analyzed only by a study with different objectives from those of the present study. $^{13}$

It is highlighted that the analysis of this potential contributes with information about the neurophysiological basis of the central auditory processing of the different acoustic stimuli. Likewise, it is a promising evaluation tool, considering the advantages presented by this procedure. Hence, it becomes useful for the clinical evaluation routine, for the monitoring of different speech-language-hearing disorders and for the contribution to national scientific researchers on auditory electrophysiology.

\section{Conclusion}

It was possible to record MMN with verbal and nonverbal stimuli in children with typical development and, based on the data obtained, it was concluded that the ear, gender and age variables did not influence on the recording of the MMN. In addition, the latency, the duration and the area of the MMN with verbal stimuli were higher. Therefore, it was possible to provide reference values for this potential for children with typical development. 


\section{Conflict of Interests}

The authors have no conflict of interests to declare.

\section{References}

1 Frizzo ACF, Reis ACMB. Potencial Evocado Auditivo de Longa Latência: Parâmetros técnicos. In: Menezes PL, Andrade KCL, Frizzo ACF, Carnaúba ATL, Lins OG. Tratado de Eletrofisiologia para a Audiologia. Ribeirão Preto: Booktoy; 2018:129-137

2 Roggia SM. Mismatch Negativity (MMN). In: BOECHAT, E.M. et al. Tratado de Audiologia. Rio de Janeiro: Guanabara Koogan; 2015: 151-159

3 Näätänen R, Gaillard AWK, Mäntysalo S. Early selective-attention effect on evoked potential reinterpreted. Acta Psychol (Amst) 1978;42(04):313-329

4 Sussman ES, Chen S, Sussman-Fort J, Dinces E. The five myths of MMN: redefining how to use MMN in basic and clinical research. Brain Topogr 2014;27(04):553-564

5 Näätänen R, Sussman ES, Salisbury D, Shafer VL. Mismatch negativity (MMN) as an index of cognitive dysfunction. Brain Topogr 2014;27(04):451-466

6 Näätänen R, Paavilainen P, Rinne T, Alho K. The mismatch negativity (MMN) in basic research of central auditory processing: a review. Clin Neurophysiol 2007;118(12):2544-2590

7 Sussman E, Ceponiene R, Shestakova A, Näätänen R, Winkler I. Auditory stream segregation processes operate similarly in schoolaged children and adults. Hear Res 2001;153(1-2):108-114

8 Ferreira DA, Bueno CD, de Costa SS, Sleifer P. Mismatch Negativity in Children: Reference Values. Int Arch Otorhinolaryngol 2019;23 (02):142-146

9 Rocha-Muniz CN, Befi-Lopes DM, Schochat E. Mismatch negativity in children with specific language impairment and auditory processing disorder. Rev Bras Otorrinolaringol (Engl Ed) 2015;81(04):408-415

10 Fu M, Wang L, Zhang M, Yang Y, Sun X. A mismatch negativity study in Mandarin-speaking children with sensorineural hearing loss. Int J Pediatr Otorhinolaryngol 2016;91(03):128-140

11 Koravand A, Jutras B, Lassonde M. Abnormalities in cortical auditory responses in children with central auditory processing disorder. Neuroscience 2017;346(05):135-148. Doi: 10.1016/j. neuroscience.2017.01.011

12 Carter Leno V, Chandler S, White $\mathrm{P}$, et al. Alterations in electrophysiological indices of perceptual processing and discrimination are associated with co-occurring emotional and behavioural problems in adolescents with autism spectrum disorder. Mol Autism 2018;9:50

13 El- Beltagy R, Galhom D, Hassan MEL. Auditory brainstem response and speech mismatch negativity in children with phonological disorders. Egypt J Otolaryngol 2019;35(01):79-85

14 Kurtzberg D, Vaughan HG Jr, Kreuzer JA, Fliegler KZ. Developmental studies and clinical application of mismatch negativity: problems and prospects. Ear Hear 1995;16(01):105-117

15 Roggia SM, Colares NT. Mismatch Negativity em pacientes com distúrbios do processamento auditivo (central). Rev Bras Otorrinolaringol (Engl Ed) 2008;74(05):705-711

16 Bishop DVM, Hardiman MJ, Barry JG. Lower-frequency event-related desynchronization: a signature of late mismatch responses to sounds, which is reduced or absent in children with specific language impairment. J Neurosci 2010;30(46):15578-15584

17 Soares AJC, Sanches SGG. Neves- Lobo IF, Carvalho RMM, Matas CG, Cárnio MS. Potenciais evocados auditivos de longa latência e processamento auditivo central em crianças com alterações de leitura e escrita: dados preliminares. Arq Int Otorrinolaringol 2011;15(04):486-491

18 Romero ACL, Capellini AS, Frizzo ACF. Potencial cognitivo em crianças com transtorno do déficit de atenção com hiperatividade. Rev Bras Otorrinolaringol (Engl Ed) 2013;79(05): 609-615

19 Haapala S, Niemitalo-Haapola E, Raappana A, et al. Effects of recurrent acute otitis media on cortical speech-sound processing in 2-year old children. Ear Hear 2014;35(03):e75-e83

20 Choudhury NA, Parascando JA, Benasich AA. Effects of Presentation Rate and Attention on Auditory Discrimination: A Comparison of Long-Latency Auditory Evoked Potentials in School-Aged Children and Adults. PLoS One 2015;10(09):e0138160

21 Massa CGP, Rabelo CM, Matas CG, Schochat E, Samelli AG. P300 with verbal and nonverbal stimuli in normal hearing adults. Rev Bras Otorrinolaringol (Engl Ed) 2011;77(06):686-690

22 Organização Mundial da Saúde- OMS. 2014 [Internet]. From: http:// www.who.int/pdb/deafness/_hearing_impairment_grades/en/

23 Jerger S, Jerger J. Alterações auditivas: um manual para avaliação clínica. São Paulo: Atheneu; 1989

24 Nunes CL, Pereira LD, Carvalho GS. Scale of Auditory Behaviors and auditory behavior tests for auditory processing assessment in Portuguese children. CoDAS 2013;25(03):209-215

25 Pereira LD, Schochat E. Testes auditivos comportamentais para avaliação do Processamento Auditivo Central. São Paulo: Pro Fono; 2011

26 Keith RW. Randon gap detection test St. Lois. Auditec; 2000

27 Wilson RH, Moncrieff DW, Townsend EA, Pillion AL. Development of a 500-Hz masking-level difference protocol for clinic use. J Am Acad Audiol 2003;14(01):1-8

28 Martins QP, Faccin VA, Brückmann M, Gil D, Garcia MV. Masking Level Difference in schoolchildren: environmental analysis. CoDAS 2018;30(03):e20170048

29 Sanju HK, Kumar P. Comparison of Pre-Attentive Auditory Discrimination at Gross and Fine Difference between Auditory Stimuli. Int Arch Otorhinolaryngol 2016;20(04):305-309

30 Schwade LF, Didoné DD, Sleifer P. Auditory Evoked Potential Mismatch Negativity in Normal-Hearing Adults. Int Arch Otorhinolaryngol 2016

31 Aerts A, van Mierlo P, Hartsuiker RJ, Santens P, De Letter M. Sex differences in neurophysiological activation patterns during phonological input processing: an influencing factor for normative data. Arch Sex Behav 2015;44(08):2207-2218

32 Ponton CW, Eggermont JJ, Kwong B, Don M. Maturation of human central auditory system activity: evidence from multichannel evoked potentials. Clin Neurophysiol 2000;111(02): 220-236

33 Morr ML, Shafer VL, Kreuzer JA, Kurtzberg D. Maturation of mismatch negativity in typically developing infants and preschool children. Ear Hear 2002;23(02):118-136

34 Pakarinen S, Teinonen T, Shestakova A, et al. Fast parametric evaluation of central speech-sound processing with mismatch negativity (MMN). Int J Psychophysiol 2013;87(01):103-110

35 Steinschneider M, Fishman YI, Arezzo JC. Representation of the voice onset time (VOT) speech parameter in population responses within primary auditory cortex of the awake monkey. J Acoust Soc Am 2003;114(01):307-321

36 Shankarnarayan VC, Maruthy S. Mismatch negativity in children with dyslexia speaking Indian languages. Behav Brain Funct 2007; $3(36): 36$ 